\title{
Araçsal Akla ve Pozitivizme Karşı çıkan Bir Feminist Metodoloji
}

\author{
A Feminist Methodology that Opposes \\ Instrumentalist Reason and Positivism
}

\section{Deniz Tansel Ilic Pinar Yıldırım****}

\begin{abstract}
Öz
Araçsal aklın bilimsel alandaki temel çıktısı olan pozitivizmin yansımaları, yalnızca nicel veri üretimi alanıyla sınırlı kalmayarak, ataerkilliğin de içinde yer aldığ1 anaakım dünya görüşünün güçlenip yerleşikleşmesinde etkili olmaktadır. Ataerkil yapıyı dönüştürerek, kadınların seslerinin hem bilim insanları olarak metin üretiminde, hem de üretilen metinlerin içindeki kadın temsillerinde yaygınlaştırılmasını talep eden feminist teorinin ve metodolojinin de, bu bağlamda pozitivizm ile arasına belli bir mesafe koyması gerekli görünmektedir. Bu çalışma, feminist metodolojinin geleneksel araştırma yöntemleri ile arasına mesafe koyabilme becerisini tartışmayı denemektedir. Feminizm; liberal, radikal, Marksist, kültürel, varoluşçu ve postmodern başlıklarıyla birbirinden ayrışmış alt dallara sahip olduğu için pozitivizm ve araçsal akıl kavramlarını genelleyerek tartışmak olası görünmemektedir. Bu metin, farklı feminist teorileri ve metodolojileri ayrımlarıyla ele aldıktan sonra, Dorothy Smith ve Sandra Harding'in, araçsal
\end{abstract}

*Yrd. Doç. Dr., Başkent Üniversitesi, İletişim Fakültesi, Radyo Televizyon ve Sinema Bölümü, deniztansel@gmail. com

** Yarı Zamanlı Öğr. Gör., Bilkent Üniversitesi, Türkçe Bölümü, pinar.yildirim@bilkent.edu.tr 
araştırma yöntemi, pozitivizm, araştırma öznesi ve nesnesi olarak kadının konumu gibi metodolojik konulara dair tezlerini ele almayı denemektedir. Çalışma, bu iki feminist yazarda varolan metodolojik eğilimlerin anaakım, pozitivist ve gelenekselci olmaktan uzak olduğunu; bu haliyle, araştırma tercihlerine dair bu muhalif duruşun yalnızca bilimsel yöntemin, araçsal akıldan arındırılmasına değil, kadınların özgürleşimlerine de katkıda bulunduğunu iddia etmektedir.

Anahtar sözcükler: Araçsal akıl, pozitivizm, feminizm, Sandra Harding, Dorothy Smith

\begin{abstract}
The reflections of positivism, the basic output in the scientific field of instrumental reasoning, are not confined to quantitative data production, but also influence the strengthening and establishment of the mainstream worldview in which patriarchy is included. It seems necessary for feminist theory and methodology, which transforms patriarchalism, to spread the voices of women both in the production of texts as scientists, and in the representations of women in the texts produced, to establish a certain distance from positivism. This study attempts to discuss the feminist methodology's ability to distance itself from traditional research methods. It is unlikely to discuss positivism and instrumental intellectual concepts in general, as feminism has different subtitles such as liberal, radical, Marxist, cultural, existentialist and postmodern. This text firstly deals with the distinctions between different feminist theories and methodologies, then attempts to address to the theses of Dorothy Smith and Sandra Harding about instrumental research methodology, positivism, and woman's position as research object and subject. The study suggests that the methodological tendencies in two feminisms are far from being mainstream, positivist and traditional and this opposition contributes not only to the cleansing of scientific method of instrumental reasoning but also to the liberation of women.
\end{abstract}

Keywords: instrumental reason, positivism, feminism, Sandra Harding, Dorothy Smith

\title{
Giriş
}

Feminizmin tarihçesi ve farklı feminizmler ekseninde ilerleyen bu çalışmanın ilk bölümü, ayrı bir feminist metodoloji olup olmadığını tartışmaktadır. Metinde, geleneksel sosyal bilim metodolojilerine feminist araştırmaların ne gibi eleştirilerde bulundukları değerlendirildikten sonra, özne-nesne ilişkileri çerçevesinde, kadının "bilen” özne olup olmadığı ve nesne ile olan konumu ele alınmaktadır. Bu bağlamda, Sandra Harding ve Dorothy Smith'nin yazılarına başvurularak, pozitivist yöntemlerin yanı sıra, yapıçözüm, hermeneutik ve diyalektik gibi farklı yöntemlerin de kullanılabileceği iddia edilmektedir.

Çalışma, akademik metinlerde kadınların "özne” olarak kurulabilmesine katkı sağlamayı amaçlamaktadır. Sosyal bilimlerin erkek merkezli formüle edildiğini; bu erkek merkezli formülasyonda, öznenin "bilen erkek", nesnenin ise "kadın" ve "doğa" olarak kabul edildiğini savunmaktadır. Metinde, ayrı bir feminist yöntemin henüz olmadığı, po- 
zitivist yöntemlerin kadın çalışmalarında tutarlı sonuçlar vermediği iddia edilmektedir. Ayrı bir feminist yöntemin varlı̆̆ iddiası yerine, feminist araştırmalarda diyalektik bir anlayışın gözetilmesinin ve bir yöntem olarak pozitivist olmayan, yorumsamacı yöntemlerin kullanılmasının kadın çalışmalarına katkıda bulunacağı, metnin temel iddialarındandır. Bu bağlamda, farklı feminizmler gibi, farklı kadın deneyimlerinin de varolduğu bir veri olarak kabul edilmektedir. Bu nedenle feminizm araştırmalarında tek tek kadın deneyimlerinin dikkate alınmasının önemli olduğu, araştırmacının nesnelliğini savunan bir yaklaşımın, araçsal aklın bilimsel karşılığı olan pozitivizmi sarsabileceği iddia edilmektedir.

\section{Feminist metodolojinin geleneksel metodoloji çalışmalarından farkı}

Feminist metodoloji; liberal, radikal, Marksist, kültürel, varoluşçu ve postmodern gibi farklı yönelimlere sahip "feminizmlerden" oluşur. Bütünlüklü bir feminist metodolojiden bahsetmek olanaksız olduğu için, feminist metodolojinin, geleneksel metodolojiden farklı olup olmadığı sorusuna basitçe olumlu veya olumsuz yanıt vermek mümkün değildir. Örneğin, Marksist feminist metodun gelenekselliği veya yenilikçiliği için söylenebilecekler, liberal feminizm için geçerli olmayacaktır. Bu nedenle, feminist metodolojinin geleneksel yöntem ile karşılaştırılmasında, bu farklı feminizmlerin her biri için ayrı bir değerlendirme yapmak gerekmektedir.

Liberal feminizm, kadın ve erkeğin eşitliği savunusunu akla dayandırdı̆̆ı, bireylerin özgürce eyleyen aktörler olduğunu iddia ettiği, anahtar kavramı doğal haklar olduğu için, (Donovan, 2009: 28), feminist teorinin geleneksel yönteme yaklaştı̆̆ dallarından biridir. Liberal feminizmin akla yaptığı olumlayıcı vurgu, Akıl Tutulması (Horkheimer, 2016) ve Aydinlanmanın Diyalektiği (Adorno ve Horkheimer, 2016) kitaplarında eleştirilen, araçsal akıl kavramına denk düşmektedir. Aydınlanma geleneğinin aklı yüceltip duyguları ve sezgileri yok sayan yanı, pozitivist metodun art alanını oluşturmaktadır. Yalnızca sayılabilir olana bakarak, nitel olanı göz ardı eden bu araştırma metodu, Aydınlanmadan ve onun temel dayanağı olan aklın yüceltilmesinden güç almaktadır. Bu bakışa göre, gözlem ve deney yoluyla ulaşılamayan bilgiler, akıldışıdır ve bu nedenle bilimsel değildir. Bu durum bir bilen özne olarak araştırmacının, kendisini araştırma konusundan ayrı tuttuğu metodoloji ile ilişki içerisindedir.

Liberal feminizmdeki doğal haklar vurgusunun da aynı şekilde geleneksel olduğu söylenebilir. Bu tez, toplumsal sözleşme ile başlayarak, 20. yüzyllın küresel-kapitalist konjonktürüne kadar giden liberal söyleminin özünü oluşturmaktadır. Bireylerin özgürce eyleyen failler / aktörler olduğu iddiası da, yapısal eşitsizlikleri yok sayan ve toplumsal yapının, tüm öznelerini aynı güce sahipmiş gibi gösteren burjuva iyimserliğiyle özdeş görünmektedir. Liberal feminizmin, kadınlar arasındaki sınıfsal farklılıklara odaklanmadığı için, kapitalizmle uyumlu olduğu düşünülebilir.

Kadınların ve erkeklerin eşit olduğu iddiası ise, hem biyolojik, hem de sınıfsal ay- 
rımları ortaya koymada yetersiz görünmektedir. İnsanları, bireyler olarak kutsayan liberal kuramdaki geleneksellik, kadınların erkeklerle eşit olduğu şeklindeki indirgemeci ve içeriği belirsiz savına içkindir. Bu savın, ataerkil yapının, kadınlar üzerine kurduğu tahakküm yapılarını anlatmakta da yetkin olmadığı öne sürülebilir. Dolayısıyla, liberal feminizmin geleneksel metodolojiden farkı olmadığı iddia edilebilir.

Belli açılardan, liberal feminizme karşıt olmasına karşın, liberalizmle belirgin benzerlikler taşıyan kültürel feminizmin de, geleneksel metodolojinin sınırlarını aşamadığı$\mathrm{n} 1$ öne sürebiliriz. Kültürel feminizm, liberal feminizmin aksine hayatın akıldışı, sezgisel ve duygusal yanları üzerinde durur (Donovan, 2009: 70). Kültürel feminizm, kadının barışsever, işbirlikçi ve şiddet karşıtı olduğunu savunur; bu özellikleri taşıyan kadınsı bir kültürün oluşturulmasını hedefler. Kültürel feminizmdeki, "kültürel” vurgusu, kadına içkin olan bu özelliklerin, kültüre de taşınmasına yönelik amaçtan kaynaklanmaktadır.

Kültürel feminizmin, duygusal ve sezgisel olana vurgu yaptığı için, Batı felsefesi geleneğini, ampirizmi ve pozitivizmi aşmakta, liberal feminizme kıyasla bir adım daha ileri gittiği kabul edilebilir. Ancak belli özellikleri nedeniyle, kültürel feminizmin, geleneksel yönleri olduğunu vurgulamak yerinde olacaktır. Bu geleneksel özelliklerden birincisi, kadının erkekten daha duygusal olduğu fikrinin sınanamazlığıdır. Tezin bilimdışı özelliğine ek olarak, kadının doğuştan duygusal, sezgisel ve barışçıl olduğu fikri, biyolojik determinist bir iddia olarak değerlendirilebilir. Kültürellik vurgusunu ismine taşıyan kültürel feminizmin, kadın ve erkek arasındaki farklılıkların kültürel olarak oluştuğunu görememiş olması, bir paradoks olarak nitelendirilebilir. Bu nedenle insanların biyolojik olarak belirlendiğini savunan bu feministlerin iddialarını, özcü, anadamar ve geleneksel olarak adlandırmak yanlış olmayacaktır. Yenilikçi metodun temel savı olan eşitlik vurgusunun ise, özcülük içerisinde yeşermesi olası görünmemektedir.

Kültürel feminizm, duygulara yaptığ 1 vurgu çerçevesinde, aklı yücelten liberal feminizme karşı çıksa da, bu yaklaşımın kendini önceleyen akımla benzerlikleri de bulunmaktadır. Feminizmin liberal ve kültürel formlarının her ikisi de bireycidir. Liberalizmdeki bireycilik vurgusu aşikâr olmasına karşın, kültürel feminizmdeki bireycilik vurgusu biraz daha belirsiz görünmektedir.

Açıklamak gerekirse, duygulara ve sezgilere değinen romantizm (coşumculuk) akımından beslenen kültürel feminizm, Josephine Donovan'ın (2009) belirttiği gibi, "romantik birey anlayışı" üzerine kuruludur. Bu anlayışa göre, her birey, üzerine eşsiz bir desen damgalanmış olarak dünyaya gelir. Doğuştan gelen niteliklere değinen bu tarz bir birey algısı ise, özcülük ve bireycilik fikri ile ilişkilidir. Bu nedenle kültürel feminizmin de, doğuştan gelen özellikleri, biyolojik determinizmi, özcülüğü ve bireyciliği nedeniyle geleneksel metodolojiyi aşacak bir alet çantası sağlayamadığı iddia edilebilir.

Feminizmin en marjinal versiyonunu, ilk dönemlerinde Marksist erkeklerle birlikte çalışmış olmalarına karşın, sonrasında sol görüşe bir karşı çıkış şeklinde geliştiren radikal feministlerde bulmak mümkündür. Radikal feministler, Marksizm'in sorunsalını, 
toplumsal olarak belirlemesine karşı çımaktadır. Bu nedenle, radikal feminizmin bilinen en temel savı, "kişisel olan politiktir" iddiasıdır (Donovan, 2009: 166). Marksizm'in bireysel olanı açıklamadaki yetersizliğini kapatsa ve psikolojiyi araştırmasına katsa da, radikal feminizmin de, toplumsaldan kaynaklanan sorunları açıklamakta yetersiz kaldığını düşünebiliriz. Heteroseksüellik, hamilelik, tecavüz gibi konularda iddialı ve yenilikçi gibi görünen yaklaşımları olmasına karşın, radikal feminizm de, bireysel olanla uğraştığ 1 için toplumsal bağlamı kaçırmış gibidir.

Varoluşçu feminizm ise, Soren Kierkegaard, Martin Heidegger, Jean Paul Sartre ve Friedrich Nietzsche gibi varoluşçu filozofların tezlerini feminizm alanına taşımaya çalışmaktadır. Varoluşçuluk, insanın ölüme yazgılı bir şekilde evrene firlatılmış olduğunu, hayatın verili bir anlamdan yoksunluğu nedeniyle kaygı yaşadığını ve yaşamı saçmadan kurtarmak için seçimler yapmak zorunda olduğunu savunur. Simone de Beauvoir, Sartre'daki "cehennem olarak öteki" fikrini kendi yazınına ekler ve erkeğin, kadını "öteki” haline getirdiğini iddia eder. Varoluşçu feminizmdeki geleneksel yan da benzer bir şekilde bireyciliktir. Bireyin özgürce eylediğini savunmak, yapısal olarak kısıtlanan öznenin, ataerkil yapının içine sıkışmış kadının tutsaklığını ortaya koymakta yeterli olmayabilir. Ayrıca varoluşçu feminizmde, Marksist feminizmdeki sınıfsal ayrım vurgusu olmadığı için, varoluşçu feminizmin de geleneksel niteliklere sahip olduğu iddia edilebilir.

Ağırlıklı olarak Karl Marx'ın arzusu üzerine, Friedrich Engels tarafından yazılan Ailenin, Özel Mülkiyetin ve Devletin Kökeni (2010) başlıklı kitabına yaslanan Marksist Feminizm ise, sol literatürün, emek üzerine tezlerini, kadın emeği üzerinden yeniden okur ve kapitalizmin, kadının emeğini değersizleştirdiği iddiası üzerine kurulur. Marksizm, sosyal bilimlerde eleştirel algının temel sacayaklarından birini oluşturmasına karşı, Marksizm üzerine birkaç eleştiri yapmak gerekli görülmektedir. Kadınlar arasındaki sınıfsal ayrımların önemini ortaya koyması açısından, Marksist teorinin feminizme yapacağı katk1 değerli olmasına rağmen, Marksizm bireye dair olan1, psikolojik unsurları açıklamakta kısır kalabilmektedir. Ezilmenin, tahakkümün, iktidarın yalnızca toplumsal olan üzerinden açıklanması mümkün olmayabilir.

Marksist kuram, gerçekliği her yönüyle açıklamaya girişen bir büyük anlatıdır. Ancak açıklanmaya çalışılan sözkonusu "gerçekliğin" bütünlüklü olduğu kuşkuludur. Postmodern teori, tek bir anlatının gerçekliği açıklamadaki yetersizliğini ortaya koyarak, "monolitik söylemin tiranlığı"na (Donovan, 2009) karşı çıkar. Ayrıca bu yeni dönem feminizm; liberal, kültürel ve varoluşçu feminizmin aksine, kadınlar arasındaki bireysel farkl111kları kabul eder.

Postmodern feminizm, beyaz olmayan, engelli, yaşlı ve lezbiyen kadınların özgüllüklerinin altını çizer. Bütünlüklü bir bilim algısına, batılı geleneksel bilime şiddetle direnir ve "güçlü bir inançsız çok dilliği" savunur (Donovan, 2009: 364). Bu haliyle postmodern feminist metodoloji, belli oranlarda, araçsal aklın ve pozitivizmin bütünlüklü dünya algısına ve nesnellik savunusu yapan bilimsellik anlayışına karşı çıkma potansiyeli taşıyabilir. 


\section{Sandra Harding: Kadın deneyimini öznel bakışla ele alan bilimsel metodoloji}

Farklı feminizm türlerinin, kadın deneyimini ele alışlarındaki geleneksel yanlarını eleştiren yazarlardan biri Sandra Harding'dir. Ayrı bir feminist metodolojinin olmad1ğını savunan Sandra Harding, "Introduction: Is there a Feminist Method?" başlıklı makalesinde gözlem yapmak, bilgi verenleri dinlemek ve tarihi kanıtları incelemek üzere üç veri toplama yöntemine dayanan (1987: 2) geleneksel sosyal bilim metodolojisi ile feminist araştırma yapılmasının mümkün olmadığını belirtir. Bunun yerine, "en iyi feminist araştırma yöntemi"nin özellikleri saptanmalı ve bu yönteme uygun bir feminist araştırma kurgulanmalıdır (1987: 1).

Yazara göre, kadını var olan geleneksel metodolojilere eklemenin ötesine geçen feminist metotların birinci özelliği, kadınların deneyimlerini incelemesidir. Yalnızca burjuva erkeğin perspektifinden yapılan araştırmalar yanıltıcı olduğu için, feminist yöntemin, problematiğini kadınların deneyimlerine dayandırması gerekir (Harding, 1987: 6-7).

Geleneksel sosyal bilimlerde, bilimsel araştırmanın mantığının beyaz erkekler tarafindan belirlendiği; erkeklerin, merak ettikleri toplumsal olayları sorunsallaştırdığı söylenebilir. Örneğin erkek araştırmacılar, bir araştırma kurguladıklarında, genellikle erkeklerin cinsiyet politikasına dokunmayan yasal bir düzenleme üzerine çalışmaktadır. $\mathrm{Bu}$ nedenle, klasik çalışmaların erkek merkezli olduğu iddia edebiliriz. Bu çalışmalar, genel olarak kadının bilen özne olması ihtimalini reddeder, bu metinlerde bilim dili erkeklere özgüdür, tarih yalnızca erkeklerin bakış açısından yazılır, çalışılacak konular erkekler için belirlenir. Geleneksel sosyal bilim çalışmalarının, kadın ve erkekleri nasıl kavramsallaştırdığına eleştirel bir gözle bakılması gereklidir. Bu nedenle, feminist çalışmalar, kadın deneyimlerine dair konulara, içeriden ve öznel sorular sormaya çalışmalıdır.

Yazara göre, temel amacının kadın olması, feminist araştırmanın ikinci özelliğidir. $\mathrm{Bu}$ tür bir araştırma, erkek için kurgulanan geleneksel araştırmanın aksine, kadınların ihtiyaç duyduğu açıklamaları sağlamalıdır (1987: 8). Bu tür sosyal bilim çalışmalarında, araştırmacının kadınlarla ilgili çalışma yapması anlamlı olacaktır.

Harding'e göre, feminist araştırmanın üçüncü özelliği, araştırmacının pozitivizmdeki "bilen özne" fikrine karşı koyması ve kendisini araştırma nesnesinden ayırmamasıdır. Araştırmacıdan beklenen, pozitivizmin değer-yansız bilim insanı mitinin olanaksızlı̆̆ını kavramasıdır. Araştırmacının sınıf, etnik köken, kültür ve toplumsal cinsiyet gibi konulardan kaynaklanan ayrışmış bir konumu vardır ve bu ayrışmış konumu araştırmaya dâhil etmek değerlidir. Araştırmacının, tüm bu yatkınlık, birikim ve konumlardan kaynaklanan ayrışmış pozisyonunu gizlemeye çalışarak, "nesnel" olmayı denemesi olası değildir. Aksine bu ayrımlar, araştırmacının şekillendirmeyi amaçladığı araştırmayı etkileyecek (1987: 9) ve araştırmaya "değer" katacaktır. Harding'in, araştırmacının otonom bir otorite sesi olmadığ 1 şekildeki vurgusu, temel bir pozitivizm eleştirisidir. Araştırmacı, pozitivizmin iddia ettiğinin aksine, somut arzuları ve ilgileri olan tarihsel bireydir. Bu nedenle objektif 
araştırma yapılabileceği iddiasından uzaklaşmak ve araştırmacıların inançlarını, "kanıtın" bir parçası olarak görmek gerekmektedir (1987: 9).

Harding, makalesinden iki yanlış sonuca varılabileceğini belirtmektedir: Birinci olas1 yanlış çıkarım, kadın çalışmalarında kadın deneyimlerinin tercih edilmesinin, göreceli bir tavır olarak değerlendirilmesidir. Yazar, kadınların cinsiyetçi ve cinsiyet karşıtı düşüncelerinin aynı oranda güvenilir olduğunu savunmamaktadır. Yazara göre, makaleden çıkarılabilecek ikinci yanlış fikir ise, erkeklerin kadın araştırmaları yapamayacağı sonucuna varmaktır. Harding'e göre, kuramları kusurlu olsa da, John Stuart Mill, Marx ve Engels feminist metodolojiye büyük katkıda bulunmuştur (Harding, 1987: 11). Yazar, daha anaerkil bir çerçeveden yazan bu erkek yazarların çalışmalarıyla, Marabel Morgan ve Phyllis Schagly gibi ataerkil kadın kuramcıların metinlerindeki karşıtlığın altını çizmektedir. Ayrıca erkeklerin kadınlarla ilgili deneyimlerinin değeri de teslim edilmeli, yalnızca erkek araştırmacıların girebildiği, ordu gibi ortamlara dair araştırmalarda, erkeklerin deneyimlerinden yararlanmanın gerekliliği akılda tutulmalıdır.

Özetle, bu tür çalışmalarda araştırmacı, araçsal aklın ve pozitivizmin dikte ettiğinin aksine, araştırdığ konuya belli bir mesafeden bakan, nesnel kişiler olarak görülmez. Feminist araştırmada da, benzer bir şekilde, kadınlar hem bilen, hem de özne olarak kabul edilir; öğrenmek istediklerini kendi deneyimlerinden hareketle formüle eder, neyi araştırmak istediklerine kendileri karar verir ve kendileri için araştırma yaparlar.

\section{Dorothy Smith: Kurumsal etnografya ve "Bilen" kadının keşfi}

Bilgi sosyolojisi üzerinde çalışan Kanadalı bir sosyolog olan Dorothy Smith, sosyolojinin de, diğer sosyal bilimler gibi erkek merkezli bir bakış açısına sahip olduğunu savunmaktadır. Tıpkı Harding gibi, Smith de, kadınlar için sosyal bilim yapılmasının gerekliliği vurgulamaktadır.

Çalışmalarında fenomenoloji, simgesel etkileşim ve etnometodolojiden yararlanan Smith, bunlara ek olarak, metin analizi yapmaya olanak sağlayan ve toplumsal kontrol mekanizmalarının, metinsel-söylemsel olduğunu ortaya koyan "kurumsal etnografya" (institutional ethnography) adında bir yöntem geliştirmiş; bu yöntemle, sosyolojinin erkek egemen bakıştan temizlenmesini hedeflemiştir. Smith, kurumsal etnografyayı, "insanların günlük hayatlarını şekillendiren toplumsal ilişkileri ortaya koymayı amaçlayan bir araştırma yöntemi” (1999: 10) olarak tanımlamaktadır.

Smith, geleneksel sosyal bilimler metodolojisinde "bilen" öznenin, erkek olduğunu ve nesnenin ise, buna bağlı olarak, kadınlar, siyahlar, fakir insanlar gibi ezilmiş gruplardan oluştuğunu ifade etmektedir. "Bilme" eyleminin süreçleri ve "bilinen şeylerin" doğası üzerinde çalışan bir bilim kadını olarak akademik yaşamının ilk zamanlarında, metinlerde erkekler tarafından üretilen söylemleri incelemiştir.

Karl Marx yazınına hâkim olan ve bilim yapan insanların, aslında yöneten sınıfın fikirlerini sistematize ettikleri düşüncesinden feyz alan Smith, sosyolojinin "ideoloji- 
sizleştirilerek" egemen sınıfın, yani beyaz burjuva erkeklerin ve toplumsal güç ilişkilerinden temizlenmesi gerektiğini ortaya koymuştur. Smith'e göre, metinler dolayımı ile oluşturulan söylemden kadının dışlanmasının nedeni, çağdaş toplumda hâkim konumda olanın, kadın olmamasıdır (1990: 11). Bu, Marx'ın üretim aygitlarına sahip olanların, ideolojik aygıtlara da sahip olacağı şeklindeki görüşü ile koşuttur. Sosyoloji de, hükümet, iş ve finans dünyası, profesyonel kuruluşlar, eğitim kurumları gibi, egemen kurumların güç alanından kopuk değildir (1987: 3). Bu nedenle, kadının yapması gereken, kendisine konuşma alanı, bilme ve politik olarak işleme gücü veren yeni bir dil geliştirmektir (1990: 11).

Smith, geleneksel sosyoloji çalışmalarında, erkeklerin bilen "özne" olarak kabul edildiklerine ve araştırmak istedikleri konuları, kendi ihtiyaçları doğrultusunda belirlediklerine inanmaktadır. Toplumun en az yarısını oluşturan kadınların deneyimlerinden yararlanılmadığını, bu yaşantıların yok sayıldığını veya ötekileştirildiğini düşünen Smith, sosyolojinin, öncelikle erkek egemen söylemlerden temizlenmesi ve veri olarak da, "kadınların deneyimleri”nin kullanılmasının gerektiğini savunmaktadır.

Sosyal bilimlerin kavramsallaştırılmasına karşı çıkan Smith, mevcut kavramların sorgulanmadan kullanılmasından rahatsızlık duymaktadır. "K Akıl Hastası" başlıklı makalesi kapsamında yaptığı mülakatlarda öğrencilerinin, öznelerin "bilme" eylemini sorgulamadan kabul ettiklerini vurgulamıştır. Smith, sözkonusu çalışmasında, fenomenolojiyi kullanarak metin çözümlemesi yapmakta ve kişiler arasındaki ilişkilerin nasıl oluşturulduğu ile ilgili bir içgörü geliştirmektedir. Metni okuyan kişi, ancak "içeriden" neyin ne olduğunu bilebilir; dışarıdan, nesnel bir bilen yoktur.

Smith, erkeklerin, sosyoloji alanında kavramsallaştırmayı, hangi şekillerde gerçekleştirdiklerini de ortaya koymaktadır. Ona göre (1990), erkekler "kendi başarıları"nı kavramsallaştırmakta ve bu kavramlar, sosyologlar tarafından sorgulanmadan kullanılmaktadır. Bu tür kavram üreten çalışmalarda, kadınların deneyimleri ve başarıları ise, yok sayılmaktadır. Smith, kadını dışlayan böyle bir kavramsallaştırmaya, kadının bedensel duruşundan kaynaklanan bir "bilme" eylemi ortaya koyarak karşı durmaktadır. Bütün bunlardan hareketle Smith, "kadın için sosyoloji"yi önermektedir.

Yeni sosyoloji çalışmalarında, kadınlar farklı bir duruş sergilemeli; geleneksel sosyal bilim yöntemindekinin aksine, kadın özne olarak "nesnel” olmakta 1srar etmemelidir. Smith (1990), nesnel olmak adına, nesnelere "dışarıdan" bakmak yerine, araştırmacının, araştırma nesnesine duygudaş bir içebakışla yaklaşmasını önermekte; öznelliğin gerekliliğini vurgulamaktadır.

Etnometodolojik çalışmalar, Smith'in sosyoloji ve feminizm anlayışında önemli bir yer tutmaktadır. Yazar, etnometodolojik çalışmalarda, araştırmacının kendini gruptan ayırarak, araştırma yapmasını eleştirmektedir. Araştırmacı, grupla kendini bütünleştirmeli, o grubun eylemlerinden doğacak olan gerçekliğe önem vermeli, gruba doğrudan katılmalı ve olayları kendisi yaratarak verilerini oluşturmalıdır. Smith, bu nedenle, ken- 
dini klasik etnometodolik çalışmalara dâhil etmek istemez. Bir olayı, mülakatı ya da yaşayanların herhangi bir eylemini analiz ederken, "dışarıda" kalmayı doğru bulmaz. Dışarıdan bakmayı öngören ampirik yöntemi, kısıtlayıcı olarak nitelendirir. Sosyolojik bir analiz yaparken, kendisini günlük hayattan ve dış dünyadan soyutlamak istemez.

Smith'in tüm bu tezleri, araçsal akıl dolayımıyla yapılan pozitivist araştırma yöntemlerinin nesnelci, tek-gerçekçi, sayılabilir/nicel araştırma algısına karşıt görünmektedir. Öznel deneyimin ele alınışı ve araştırmacı öznenin de bizzat bir "veri”" olarak kendisini araştırmasına katması, araçsal aklın ve pozitivizmin dikte ettiği, baskıcı araştırma yöntemlerini sarsacak gibi görünmektedir.

\section{Sonuç}

Bu çalışmanın birinci bölümünde, feminist araştırmaların geleneksel metodolojiden farklı1ıkları olup olmadığı tartı̧̧ılmıştır. Bu tartışmayı sürdürebilmek için, "ne kadar feminist teori varsa, o kadar feminist yöntem vardır" fikrinden yola çıkılmış; feminist metodoloji içerisindeki parçalıklı yapıdan bahsetmenin önemi vurgulanmıştır.

Bu amaçla, liberal, kültürel, varoluşçu, Marksist feminizmler arasındaki ayrımların sınırı çizilmiştir. Son kertede, liberal, kültürel ve varoluş̧̧u feminizmlerin bireyci özelliklerine değinilmiştir. Ayrıca, kültürel feminizmdeki özcülük fikri ile liberal kuramdaki akıl vurgusunun, anaakım metotla belli oranda uyumlu olduğu iddia edilmiştir. Marksist feminizmin, yenilikçi görünmesine karşın bireysel ve psikolojik olanı yok saydığı için, indirgemeci olabileceği iddia edilmiştir. Radikal feminizmin ise, tam tersi noktadan, kapitalist düzenin, kadın emeği üzerindeki değersizleştirici etkisini yok sayma ve yalnızca bireysel olana odaklanma ihtimali taşıdığını hatırlatılmıştır. Resmi çizilen bu feminist metodolojilerin, geleneksel metodolojiye belli oranda yakınlık taşıdığı iddia edilmiştir. Postmodern feminizmin, bütünlüklü anlatılara karşı koymayı denemesinden dolayı, yenilikçi olabileceği savunulmuştur.

Çalışmanın ikinci bölümünde, iki kadın teorisyen, Sandra Harding ve Dorothy Smith, araştırma metotlarındaki anti-pozitivist vurgular üzerinden değerlendirilmiştir. Bu iki kadın düşünür, alternatif, muhalif, yenilikçi bir feminist yöntemin oluşmasını önermekte; kadın deneyimlerinden yola çıkan, pozitivizmin nesnellik vurgusuna sırtını dönerek, öznel olan bir feminist metodolojinin yolunu açmaya çalışmaktadır.

Bu çerçevede, kadın çalışmalarında ve sosyal bilimlerin diğer alanlarında kadınların "özne” olabileceği sonucuna varılabilir. Kadınların, araştırmanın "özne”si olma, çalışacakları konulara kendi yararları için karar verebilme hakları ve yeterlilikleri vardır. Böyle bir görüş, Kartezyen felsefenin dayattığı, her şeyi "bilen”, dışarıdaki "özne" ve durağan nesne anlayışında olduğu gibi nesnellik iddiasında bulunmaz. Araştırma yapan kadının kimliğinin, sınıfının, hayat görüşünün bilinmesinin ve araştırmanın bu yönde değerlendirmesinin, sosyal bilimlere katkı yapacağına inanılır. Öznesi kadın olan çalışmalarda, yorumsamacı yöntemler de kullanılmalıdır; çünkü metinlerden erkek egemen 
söylemin ayıklanması, metinlerin tersten okunması, ana fikirlerin, kadın bakış açısıyla yeniden araştırma sorularının oluşturulması, tutarlı sosyal bilimlerin yapılabilmesi için önem taşımaktadır.

Sonuç olarak, sosyal bilimlerde ayrı bir "feminist" duruşun ya da yöntemin olabileceğini, ancak farklı bir feminist metodoloji bulunmadığını iddia edebiliriz. Ancak kadın deneyimlerinden yararlanmayı ve kadının hem araştırılan, hem de araştırmacı olmasını öngören "yeni bir feminist yöntem”, mantıklı bir çözüm gibi görünmektedir.

\section{Kaynaklar}

Adorno, T. ve Horkheimer, M., (2016). Aydınlanmanın diyalektiği. (Çev. E. Öztarhan, N. Ülner). İstanbul: Kabalc1.

Donovan, J. (2009). Feminist Teori: Amerikan feminizminin entelektüel gelenekleri. (Çev. A. Bora). İstanbul: İletişim.

Engels, F. (2010).. Ailenin, özel mülkiyetin ve devletin kökeni. (çev. K. Somer). Ankara: Sol. Horkheimer, M. (2016). Akul tutulması. (Çev. O. Koçak). İstanbul: Metis.

Harding, S. (1987.) Introduction: Is there a feminist method? Feminism and methodology, Indiana: Open University.

Smith, D. (1987). The everyday world as problematic, a feminist sociology. Northeastern University Press: Boston.

Smith, D. (1990). The conceptual practices of power. Northeastern University Press: Boston. 